\title{
KRAS, EGFR, PDGFR- $\alpha$, KIT and COX-2 status in carcinoma showing thymus-like elements (CASTLE)
}

Lothar Veits ${ }^{1 *}$, Rupert Schupfner ${ }^{2}$, Petra Hufnagel ${ }^{3}$, Roland Penzel ${ }^{4}$, Jens Freitag ${ }^{5}$, Philipp Ströbel ${ }^{6}$, Michael A Kern ${ }^{4}$, Sören Schröder ${ }^{7}$, Nikolaus Neuhold ${ }^{8}$, Kurt W Schmid ${ }^{9}$, Peter Schirmacher ${ }^{4}$, Arndt Hartmann ${ }^{10}$ and Ralf J Rieker ${ }^{10}$

\begin{abstract}
Background: CASTLE (Carcinoma showing thymus-like elements) is a rare malignant neoplasm of the thyroid resembling lymphoepithelioma-like and squamous cell carcinoma of the thymus with different biological behaviour and a better prognosis than anaplastic carcinoma of the thyroid.

Methods: We retrospectively investigated 6 cases of this very rare neoplasm in order to investigate the mutational status of KRAS, EGFR, PDGFR- $a$ and KIT, as well as the immunohistochemical expression pattern of CD117, EGFR and COX-2, and possibly find new therapeutic targets.

Results: Diagnosis was confirmed by a moderate to strong expression of CD5, CD117 and CK5/6, whereas thyroglobulin, calcitonin and TTF-1 were negative in all cases. Tumors were also positive for COX-2 and in nearly all cases for EGFR. In four cases single nucleotide polymorphisms (SNPs) could be detected in exon 12 of the PDGFR-a gene (rs1873778), in three cases SNPs were found in exon 20 of the EGFR gene (rs1050171). No mutations were found in the KIT and KRAS gene.
\end{abstract}

Conclusions: All tumors showed a COX-2 expression as well as an EGFR expression except for one case and a wild-type KRAS status. No activating mutations in the EGFR, KIT and PDGFR-a gene could be detected. Our data may indicate a potential for targeted therapies, but if these therapeutic strategies are of benefit in CASTLE remains to be determined.

Virtual Slides: The virtual slide(s) for this article can be found here: http://www.diagnosticpathology.diagnomx.eu/vs/ 1658499296115016

Keywords: CASTLE, Thymic carcinoma, Mutational analysis, Immunohistochemistry, Thyroid gland

\section{Background}

Carcinoma showing thymus-like elements (CASTLE) is a rare malignant tumor of the thyroid gland. It was first described by Miyauchi et al. in 1985 as "intrathyreoidal epithelial thymoma" [1], is thought to arise from ectopic thymic tissue within the thyroid gland or rudimentary branchial pouches along the thymic line and was named CASTLE by Chan and Rosai in 1991 [2]. CASTLE-tumors belong to a group of ectopic tumors of thymic differentiation: Ectopic hamartomatous thymoma, ectopic cervical thymoma, spindle epithelial tumors with thymus like differentiation (SETTLE) and carcinoma showing thymic-

\footnotetext{
* Correspondence: Lothar.Veits@klinikum-bayreuth.de

'Institute of Pathology, Klinikum Bayreuth, Preuschwitzerstraße 101, Bayreuth 95445, Germany

Full list of author information is available at the end of the article
}

like elements (CASTLE). Although CASTLE shows some tendencies for squamous differentiation, it has newly been adopted as an independent entity by the recent WHO classification [3]. In contrast to ectopic thymomas, SETTLE and CASTLE are always malignant and therefore the exact diagnosis is crucial in consideration of prognosis and treatment. CASTLE tumors have characteristic clinical and histological features. They are tumor of the adults in the fifth decade of life and often invade the adjacent soft tissue. Metastases into the regional lymph nodes are common. The largest study yet performed comprised 25 cases [4]. According to this study it is likely that some thyroid cancers, especially those with squamous differentiation may have been treated incorrectly based on an improper classification. For our study we collected 6 cases of this rare malignancy and evaluated possible therapeutic options. 


\section{Methods}

In our study we included 6 patients suffering from CASTLE, 3 women and 3 men, diagnosed between 1997 and 2007. The median age was 60 years ranging from 30 to 68 years.

\section{Tissue microarrays and immunohistochemistry}

Tissue microarrays (TMA) were performed from the paraffin-wax-embedded blocks of the tumor specimens. A tissue arrayer device (Beecher Instruments, Sun Prairie, WI, USA) was used. All the investigated cases were reviewed and representative tumor areas were marked in the corresponding paraffin wax blocks, of which at least two were sampled. The diameter of the cylinders was $1.2 \mathrm{~mm}$. For immunohistochemistry $5 \mu \mathrm{m}$ sections on poly-L-lysine-coated slides were used after drying in an oven, followed by dewaxing and peroxidase blocking with $1 \% \mathrm{H}_{2} \mathrm{O}_{2}$. The specificity of immunostaining was tested by replacing primary antisera with normal rabbit serum. No additional pre-treatment procedure for antigen retrieval was done. The immunoreactions were performed with the following primary monoclonal antibodies: Anti-COX-2 (monoclonal rabbit IgG; Santa Cruz, USA; 1:50), anti-CD5 (monoclonal mouse IgG; Novocastra, Leica Microsystems, Wetzlar, Germany; 1:25), anti-TTF-1 (monoclonal mouse, IgG, SPT24; Menarini, Florence, Italy; 1:100), anti-CK 5/6 (monoclonal mouse IgG, M7237; Dako Cytomation, Glostrup, Denmark; 1:50), anti-Ki67 (monoclonal mouse IgG, K-2, Zytomed, Berlin, Germany; ready-to-use). Primary polyclonal antibodies used were: CD117 (polyclonal rabbit, A4502; Dako Cytomation, Glostrup, Denmark; 1:50), anti-thyroglobulin (polyclonal rabbit, A0251; Dako Cytomation, Glostrup, Denmark; 1:80000) and anti-calcitonin (polyclonal rabbit, A0576; Dako Cytomation, Glostrup, Denmark; 1:4000). After washing steps signal detection was performed (EnVision + system-HRP, AEC, Dako Hamburg, Germany; 1:200) followed by counterstaining in hemalaun. Detection of EGFR was performed with the EGFR pharmDX kit (Dako Hamburg, Germany) according to manufacturer's instructions.

The presence of clearly visible dark brown precipitation was considered as immunoreaction, evaluated by a score for staining intensity (0: no staining; 1 : weak; 2 : moderate; 3 : strong reaction intensity).

\section{Mutational analysis of KIT, PDGR-a, EGFR, KRAS}

Cores of tumor tissue selected from regions on correspondent Hematoxylin-Eosin slides were manually punched out from the donor blocks. DNA was extracted from paraffin-embedded tissue sections using EZ1 DNA tissue Kit (Qiagen, Hilden Germany) after pre-treatment with proteinase K (Qiagen, Hilden Germany). $150 \mathrm{ng}$ DNA were used for PCR amplification and all PCR reactions were run at a final volume of $25 \mu$ l (Red Jump MasterMix, Sigma-Aldrich). Exons 9, 11, 13 and 17 of KIT, exons 10, 12, 14 und 18 of PDGFR- $\alpha$, exons 18, 19, 20 and 21 of EGFR and exons 2 and 3 of KRAS were evaluated for the presence of mutations by PCR amplification and direct sequencing. The primer pairs used for PCR amplification and direct sequencing are shown in Table 1. After estimation of DNA concentration by spectroscopy (GeneQuant) relevant exons were amplified by PCR under standard conditions with an annealing temperature of $50^{\circ} \mathrm{C}$ for Exon $17(K I T), 55^{\circ} \mathrm{C}$ for Exon 2 and 3 (KRAS), Exon 9 (KIT) and Exon 18 (PDGFR), $60^{\circ} \mathrm{C}$ for Exon 18, 19, 20 and 21 (EGFR) and Exon 11 and 13 (KIT) as well as Exon 10, 12 and 14 $(P D G F R)$ with the corresponding primers. The PCR products were then separated on agarose gel containing ethidiumbromide and visualized under ultraviolet light. Afterward PCR products were purified using high pure PCR product purification kit (Roche Diagnostics, Penzberg, Germany) and then sent to Qiagen (Hilden, Germany) for sequencing according to Sanger method.

\section{Ethical approval}

This study was approved by the ethics committee of the University Hospital Heidelberg (reference number: 206/ 2005).

\section{Results}

\section{Clinical and histological characteristics}

The primary symptom was a palpable node in 2 patients and an adenomatous goitre as well as a paresis of the recurrent nerve in 1 case, respectively. In 3 cases no case history was available. 5 tumours were located in the thyroid and 1 was partially extrathyroidal, the latter with the majority of the tumor mass in the thyroid gland.

Local tumor stage was T2 in one case, T3 in 3 cases, the remaining cases T4. In 3 cases no lymph nodes were affected, 3 patients already developed lymph node metastases. All cases underwent curative hemi- or total thyroidectomy. 5 patients received postoperative radiotherapy, 1 received a combined radio- and chemotherapy. The median time of follow-up observation was 18.5 months, with a range from 2 to 36 months. During this time, 1 patient developed local recurrence 2 months after primary operation and underwent a second tumorectomy with bilateral neck dissection and transsternal lymphadenectomy. The remaining patients were recurrence-free (see Table 2). By histology the resected specimen showed fibrous septa with lobulation and surrounding tumor islands of various size (see Figure $1 \mathrm{C}+\mathrm{F}$ ). Especially the peripheral tumor tissue was infiltrated by small lymphocytes (see Figure $1 \mathrm{~A}, \mathrm{~B}$, $D, E)$. Scattered blood vessels were found, surrounded by fibrous connective tissue. 
Table 1 Primer sequences for KIT, PDGR, EGFR, KRAS PCR amplification KIT9F 5'GCC ACA TCC CAA GTG TTT TAT G KIT9R 5'GAG CCT AAA CAT CCC CTT AAA TTG

KIT11F 5'CCA GAG TGC TCT AAT GAC TG

KIT11R 5'AGC CCC TGT TTC ATA CTG AC

KIT13F 5'CTT GAC ATC AGT TTG CCA GTT GT

KIT13R 5'GAC AGA CAA TAA AAG GCA GCT TG

KIT14F 5'CTC ACC TTC TT CTA ACC TTT TCT T

KIT14R 5'CCC ATG AAC TGC CTG TCA AC

KIT17F 5'ATG GTT TTC TTT TCT CCT CC

KIT17R 5'TAC ATT ATG AAA GTC ACA GG

PDGFRA10F 5'GGC CCT ATA CTT AGG CCC TाT T

PDGFRA10R 5'TGT CCT GAC TGT TGA GGA ACT

PDGFRA12F 5'CTC TGG TGC ACT GGG ACT TT

PDGFRA12R 5'GCA AGG GAA AAG GGA GTC TT

PDGFRA14F 5'TCT GAG AAC AGG AAG TTG GTA GC

PDGFRA14R 5'CCA GTG AAA ATC CTC ACT CCA

PDGFRA18F 5'TCT TGC AGG GGT GAT GCT AT

PDGFRA18R 5'AGA AGC AAC ACC TGA CTT TAG AGA TTA

EGFR18F 5'GCT GAG GTG ACC CTT GTC TC

EGFR18R 5'ACA GCT TGC AAG GAC TCT GG

EGFR19F 5'GCT GGT AAC ATC CAC CCA GA

EGFR19R 5'GAG AAA AGG TGG GCC TGA G

EGFR 20 F 5'CAT GTG CCC CTG CTT CTG

EGFR 20R 5'GAT CCT GGT TCC TTA TCT CC

EGFR21F 5'CCT CAC AGC AGG GTC TTC TC

EGFR21R 5'CCT GGT GTC AGG AAA ATG CT

KRAS2F 5'GTG TGA CAT GTT CTA ATA TAG TCA

KRAS2R 5'GAA TGG TCC TGC ACC AGT AA

KRAS3F 5'CCA GAC TGT GTT TCT CCC TTC

KRAS3R 5'TGC ATG GCA TTA GCA AAG AC

The different exons of KIT, PDGFR, EGFR and KRAS are written in bold letters.

Tumor cells were varying in shape: Irregular cells as well as spindle-shaped and epithelioid cells were observed. Occasionally, squamoid or spindle-shaped epithelial cells with whorls resembling Hassall's corpuscles were noticed. The cytoplasm of the tumor cells was pale and nuclei were clearly evident and slightly oval (see Figure 1A - F).

\section{Immunohistochemistry}

All CASTLE cases expressed CD5 in a moderate to strong reaction and CD117 in predominantly weak to moderate intensity in the epithelial component. Only in one case a strong staining signal for CD117 could be detected. (see Figure $1 G+H$ ). Staining with CK5/6 showed weak to strong reactions in all samples (see Figure 1I). EGFR showed a strong reactivity in three, weak staining intensity in two samples and no staining pattern in one case (see Figure 1J). COX-2 was detected positively in all cases with mainly moderate expression patterns (see
Figure $1 \mathrm{~K})$. The expression of Ki67 showed varying results between $2 \%$ and $85 \%$. The staining results for CD117, EGFR, COX-2 and Ki67 are shown summarized in Table 3. All cases were negative for calcitonin, thyroglobulin and TTF-1 (Figure 1L).

\section{Mutational analysis of KIT, PDGFR- $a$, EGFR, KRAS}

Mutational analysis of KIT, PDGFR- $\alpha, E G F R$ and KRAS was possible in only 4 cases due to inapplicable DNA in case number 2 and 3 .

Mutation analysis of all four investigated cases revealed the absence of an activating mutation in the PDGFR- $\alpha$ gene of exon 10, 12, 14 and 18. Nevertheless, in all four cases a silent single nucleotide polymorphism with a base substitution (CCA >CCG) in exon 12 at codon 567 (p.P567P) of the PDGFR- $\alpha$ gene was observed. This change has already been described in the SNP database with the number rs1873778 (Figure 2A).

Table 2 Patient characteristics and tumor progression

\begin{tabular}{|c|c|c|c|}
\hline No. & Stage & Therapy & Progression \\
\hline 1 & pT4, N1b (18/21), MX, R0 & $\begin{array}{l}\text { Total thyroidectomy, left central neck dissection, resection of the left recurrent laryngeal } \\
\text { nerve and the left internal jugular vein, chemotherapy, radiation ( } 50 \mathrm{~Gy} \text { ) After recurrence: } \\
\text { Tumorectomy, bilateral neck dissection, transsternal lymphadenectomy }\end{array}$ & $\begin{array}{l}\text { Local recurrence } \\
\text { after } 2 \text { months }\end{array}$ \\
\hline 2 & pT3, NO (0/5), MX, RO & Thyroidectomy, cervico-central lymphadenectomy & $\begin{array}{l}\text { No recurrence (time of } \\
\text { observation: } 36 \text { months) }\end{array}$ \\
\hline 3 & pT3, N0, MX & Subtotal thyroidectomy, local telecobalttherapy of the neck (60 Gy) & $\begin{array}{l}\text { No recurrence (time of } \\
\text { observation: } 19 \text { months) }\end{array}$ \\
\hline 4 & pT2, N0 (0/7), MX & $\begin{array}{l}\text { Hemithyroidectomy right, then restthyroidectomy, microdissection of the cervicocentral } \\
\text { compartment, radiation of the thyroidbed }(59,4 \mathrm{~Gy})\end{array}$ & $\begin{array}{l}\text { No recurrence (time of } \\
\text { observation: } 15 \text { months) }\end{array}$ \\
\hline 5 & pT3, N1 (1/19), MX & $\begin{array}{l}\text { En bloc resection with the right lobe, neurolysis N.laryngeus recurrens right, neck } \\
\text { dissection right, supraclavicular cervical lateral dissection, radiation (50 Gy) }\end{array}$ & $\begin{array}{l}\text { No recurrence (time of } \\
\text { observation: } 17 \text { months) }\end{array}$ \\
\hline 6 & pT4a, N1 (1/5), M0, R0 & Total thyroidectomy, neck dissection, radiation of the neck region (50 Gy) & $\begin{array}{l}\text { No recurrence (time of } \\
\text { observation: } 22 \text { months) }\end{array}$ \\
\hline
\end{tabular}



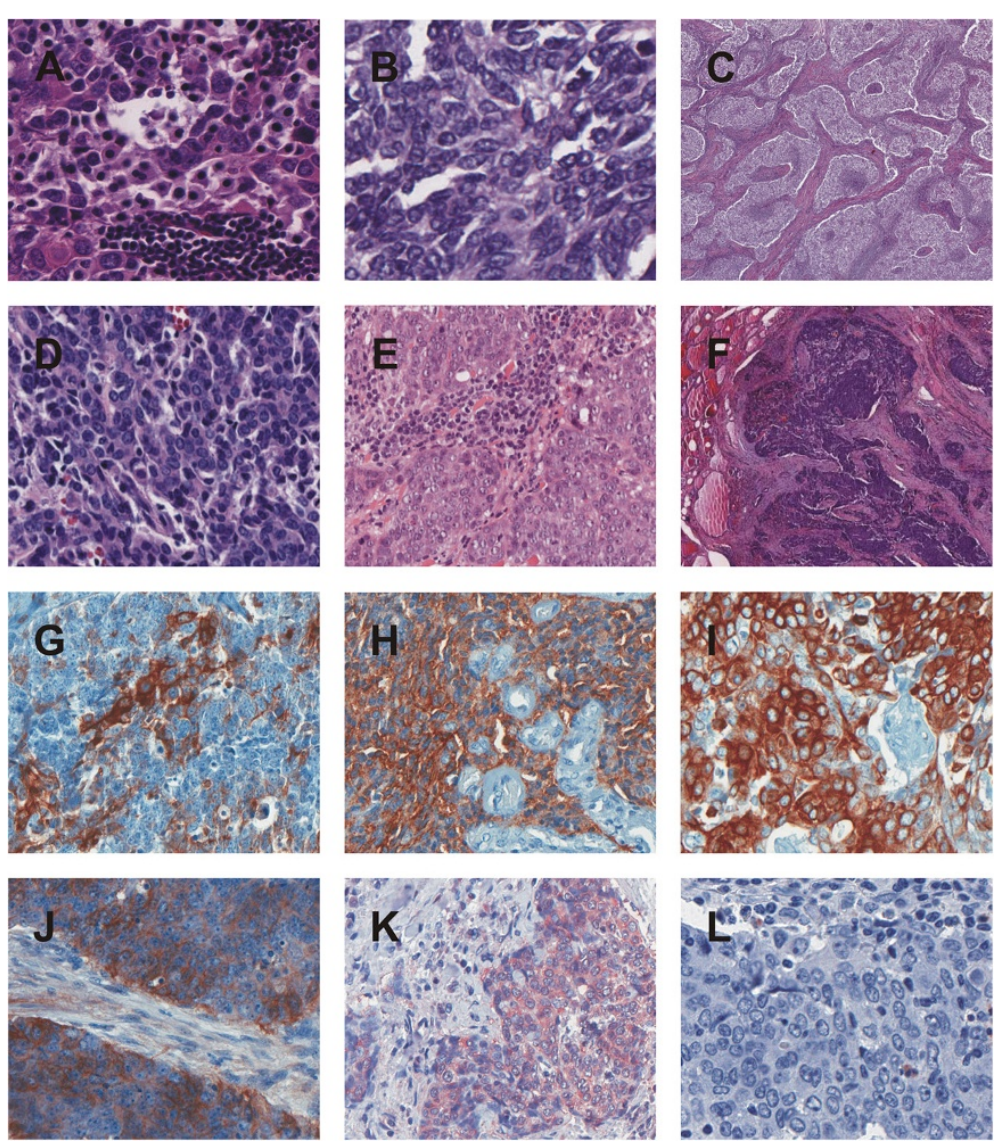

Figure 1 HE and immunohistochemical stainings. A-F. HE staining case 1-6. A. HE case 1, B. HE case 2, C. HE case 3, D. HE case 4, E. HE case 5, F. HE case 6. G-L. Immunohistochemical staining case 1-6 for CD5, CD117, CK5/6, COX-2, EGFR and TTF-1. G. CD5 case 1. H. CD117 case 5. I. CK5/6 case 4. J. EGFR case 6. $\mathbf{K}$. COX-2 case 2. L. TTF-1 case 3.

In $3(3 / 4)$ patients a silent single nucleotide polymorphism with a base substitution (CAG > CAA) in the EGFR gene of exon 20 at position 787 (p.Q787Q) was observed, which has also already been described in the SNP database with the number rs1050171 (Figure 2B). No mutation associated with drug sensitivity in the hotspot exons 18, 19, 20 and 21 was detected. No patient had detectable sequence variants for KIT in the hotspot region of exon 9, 11, 13 and 17. Also no sequence variants were found in the sequenced exons of the KRAS gene (Table 4).

\section{Table 3 Immunohistochemical expression pattern}

\begin{tabular}{lllll}
\hline No. & CD117 & EGFR & COX-2 & Ki67 (\%) \\
\hline 1 & 1 & 1 & 2 & 17 \\
2 & 2 & 3 & 2 & 7 \\
3 & 1 & 0 & 3 & 2 \\
4 & 1 & 3 & 1 & 12 \\
5 & 3 & 1 & 2 & 53 \\
6 & 2 & 3 & 2 & 85 \\
\hline
\end{tabular}

No. case number; 0 no staining, 1 weak, 2 moderate, 3 strong reaction intensity.

\section{Discussion}

CASTLE tumors are rare malignant tumors occurring in the thyroid, but the prognosis and the concomitant long term survival rate is better than for other aggressive advanced thyroid neoplasms $[1,2,5]$. Among other things and according to the so far largest study of CASTLEtumors comprising 25 cases $[4,6]$ a significant number may have been incorrectly classified, especially as squamous cell carcinoma of the thyroid. In this study Ito et al. showed a survival rate of $90 \%$ after 5 years and $82 \%$ after 10 years. Patients without lymph node metastasis had an overall survival rate of $100 \%$ after 5 years, those with lymph node metastasis $76 \%$ after 5 and $57 \%$ after 10 years. One of our patients with initial lymph node metastasis had recurrence after 2 months. No recurrence during an observation period of up to 73 months occurred in the other patients. Interestingly, the expression of Ki67 showed varying results between $2 \%$ and $85 \%$, but could not be linked to the presence of lymph node metastases or advanced tumor stages, as the only case in which a tumor recurrence was observed showed a low proliferation rate (compared to e.g. striking $85 \%$ in case 

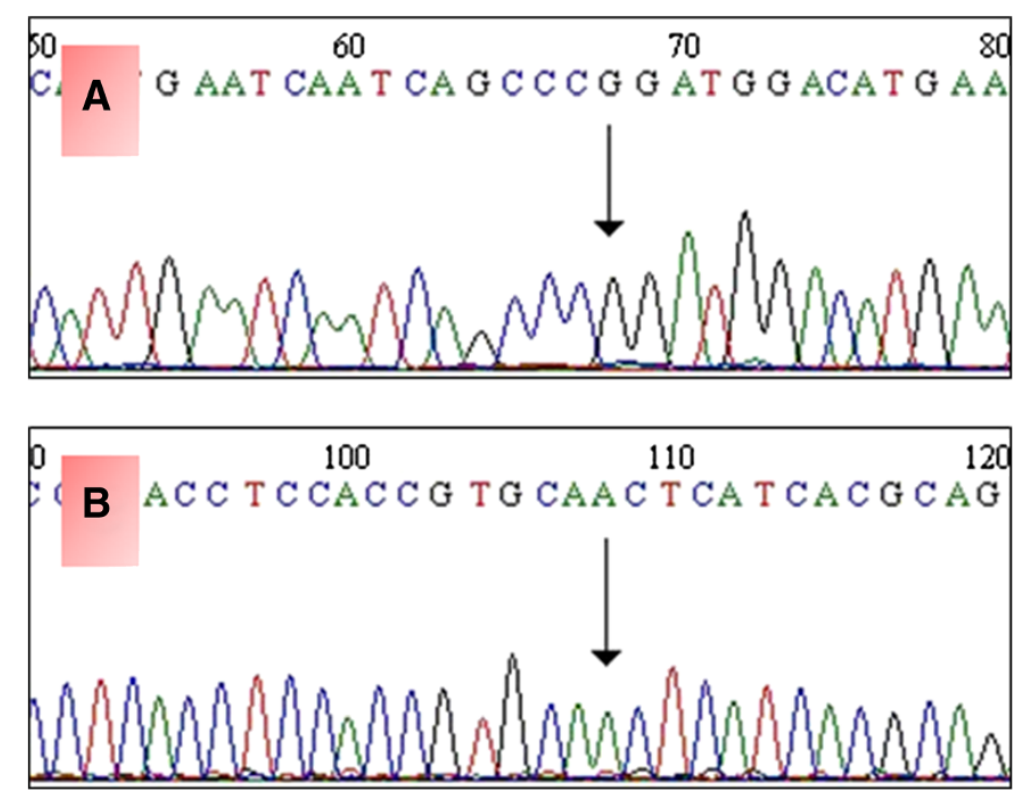

Figure 2 SNPs in PDGFR and EGFR genes. A. Forward chromatogram showing C.A1701G, predicting p.P567P in the PDGFR gene (db SNP = rs 1873778). B. Forward chromatogram showing c.G2361A, predicting p.Q787Q in the EGFR gene ( $\mathrm{db}$ SNP = rs1050171).

number 6 with no recurrence during an observation period of 22 months).

Because a diagnosis of CASTLE is difficult before resection of the tumor, patients are usually treated according to the standards of thyroid gland carcinoma with surgical removal of all or part of the thyroid gland with

\begin{tabular}{|c|c|c|c|c|c|c|}
\hline Gene & Exon & $\begin{array}{l}\text { Nucleotide } \\
\text { alt. }\end{array}$ & $\begin{array}{l}\text { Amino } \\
\text { acid } \\
\text { subst. }\end{array}$ & No. & Interpretation & dbSNP \\
\hline \multirow[t]{4}{*}{ PDGFR- $a$} & 10 & - & - & 4 & wild type & - \\
\hline & 12 & C.A1701G & p.P567P & 4 & SNP & rs1873778 \\
\hline & 14 & - & - & 4 & wild type & - \\
\hline & 18 & - & - & 4 & wild type & - \\
\hline \multirow[t]{5}{*}{ EGFR } & 18 & - & - & 4 & wild type & - \\
\hline & 19 & - & - & 4 & wild type & - \\
\hline & 20 & C.G2361A & p.Q787Q & 3 & SNP & rs1050171 \\
\hline & 20 & - & - & 1 & wild type & - \\
\hline & 21 & - & - & 4 & wild type & - \\
\hline \multirow[t]{2}{*}{ KRAS } & 2 & - & - & 4 & wild type & - \\
\hline & 3 & - & - & 4 & wild type & - \\
\hline \multirow[t]{4}{*}{ KIT } & 9 & - & - & 4 & wild type & - \\
\hline & 11 & - & - & 4 & wild type & - \\
\hline & 13 & - & - & 4 & wild type & - \\
\hline & 17 & - & - & 4 & wild type & - \\
\hline
\end{tabular}

No. Number of patients; $d b S N P$ http://www.ncbi.nlm.nih.gov/SNP/; SNP single nucleotide polymorphism; Nucleotide alt. Nucleotide alteration; Amino acid subst. Amino acid substitution. or without neck dissection. Depending on the tumor entity and stage postoperative therapy is often indicated. 5 of our patients underwent radiotherapy, 1 combined radiochemotherapy.

We have recently described chromosomal imbalances in CASTLE similar to those found in thymomas and thymic carcinomas [7]. Given the morphological, immunohistochemical and genetic similarities with thymic carcinomas, it seems reasonable to assume that treatment of advanced CASTLE should follow the guidelines for thymic tumors and patients may benefit also from evolving therapeutic options for patients with thymic tumors [8-13].

CD117 is expressed in about $86 \%$ of thymic carcinomas [14], but KIT gene mutations are uncommon. So far, only few cases of metastasizing thymic carcinoma with an activating KIT mutation and a partial response to treatment with Imatinib have been described $[15,16]$. In our analysis, all CASTLE tumors showed positive staining results for CD117, but no mutations of the KIT gene.

Membrane associated EGFR expression has been seen in thymomas as well as in thymic carcinomas. Girard summarized eight studies [17], which investigated EGFR expression levels in thymic malignancies [18-25] using immunohistochemistry. In this meta-analysis, EGFR was overexpressed in $70 \%$ of thymomas and $53 \%$ of thymic carcinomas, but there was no correlation between EGFR expression and thymic tumor type. Activating EGFR mutations seem to be exceptionally rare in thymic carcinomas with only few reported EGFR missense mutations 
in exon 21 (p.L858R in two cases and p.G863D in one case) $[23,26]$. In the present series, five tumors showed weak to strong immunohistochemical staining results for EGFR. Two of the four cases, in which DNA-extraction was successful, showed a weak positivity for EGFR, the other two cases showed a strong signal. In three cases mutational analysis revealed a single nucleotide polymorphism (SNP) in the EGFR gene of Exon 20 (p.Q787Q), but no activating $E G F R$ gene mutation could be found.

It has been shown that a therapeutic effect can be seen after the use of EGFR-inhibitors in non-small cell lung cancers, even if there is no activating mutation in the EGFR gene [27]. In a small series of advanced thymic tumours only a slight therapeutic effect could be demonstrated with Gefitinib [28].

Randomised clinical trials have demonstrated the potential of COX-inhibitors in tumor prevention [29]. Malka et al. showed that inhibition of COX-2 could play a possible therapeutic role in other tumor entities, for instance hepatocellular carcinoma [30]. In particular, the combination of COX-2 inhibitors and EGFR-inhibitors seems to increase the therapeutic effect in colon or cervical carcinoma [31-34]. COX-2 is frequently upregulated in thymomas and thymic carcinomas [11,12]. In our study all tumors expressed COX-2 raising the possibility to use COX-2 inhibitors in advanced cases.

Although in our investigation all four cases showed SNPs in the PDGFR- $\alpha$ gene of exon 12, no activating mutations in the PDGFR- $\alpha$ gene and no mutations in Codon 12 and 13 of the KRAS gene were detected.

\section{Conclusion}

As already mentioned above, CASTLE shows some similarity to thymic carcinoma. However, in the latter targeted therapy is difficult and somehow limited in advanced tumors as there are only few reported cases in which targeted therapy was of some therapeutic benefit. Ströbel et al., for example, suggest that in cases with advanced thymic carcinoma treatment with the multi-kinase inhibitor Sunitinib, that targets VEGFR1-3, PDGFR- $\alpha$, c-KIT, FLT3, colony stimulating factor-1 (CSF1) and the RET receptor, is more effective than therapeutic regimes using single-target molecular therapies like Gefitinib, even though there are no activating mutations in the EGFR, KIT and PDGFR- $\alpha$ gene [35]. In conclusion, our data may indicate a potential for targeted therapies, but if these therapeutic strategies are of benefit in CASTLE remains to be determined.

\section{Competing interests}

The authors declare that they have no competing interests.

\section{Authors' contributions}

LV generated the study concept and design, evaluated the HE- and immunohistochemical stains, analysed and interpreted the data, confirmed the diagnosis and drafted the manuscript. RS critically revised the manuscript for important intellectual content and participated in the design of the study.
$\mathrm{PH}$ carried out the molecular genetic studies, participated in the sequence alignment and analysed and interpreted the data. RP participated in the molecular genetic studies and critically revised the manuscript for important intellectual content. JF critically revised the manuscript for important intellectual content and participated in the analysis of the data. PS critically revised the manuscript for important intellectual content and participated in the study design and concept. MK carried out the immunoassays. SS critically revised the manuscript for important intellectual content and participated in the study design and concept. NN critically revised the manuscript for important intellectual content and participated in the study design and concept. KS participated in the study design and concept and critically revised the manuscript for important intellectual content. PS critically revised the manuscript for important intellectual content. AH critically revised the manuscript for important intellectual content. RR critically revised the manuscript for important intellectual content, participated in the design of the study and evaluated the HE- and immunohistochemical stains, confirmed the diagnosis. All authors read and approved the final manuscript.

\section{Authors' information}

Lothar Veits and Rupert Schupfner share first authorship.

\section{Author details}

${ }^{1}$ Institute of Pathology, Klinikum Bayreuth, Preuschwitzerstraße 101, Bayreuth 95445, Germany. ${ }^{2}$ Clinic of Trauma and Reconstructive Surgery, Klinikum Bayreuth, Preuschwitzerstraße 101, Bayreuth 95445, Germany.

${ }^{3}$ Pathologielabor Zams, Klostergasse 1, Zams 6511, Austria. ${ }^{4}$ Department of Pathology, University Hospital, INF 220/221, Heidelberg 69120, Germany. ${ }^{5}$ General practitioner, Moselstraße 1, Oberbettringen 73529, Germany. ${ }^{6}$ Department of Pathology, University Hospital, Robert-Koch-Straße 40, Göttingen 37075, Germany. 'Institute of Pathology/Lademannbogen Laboratories, Lademannbogen 61-63, Hamburg 22339, Germany. ${ }^{8}$ Pathologisch-Bakteriologisches Institut, Kaiserin-Elisabeth-Spital, Huglgasse 1-3, Vienna 1150, Austria. 'Department of Pathology and Neuropathology, University Hospital Essen, Hufelandstraße 55, Essen 45122, Germany.

${ }^{10}$ Department of Pathology, University Hospital Erlangen, Krankenhausstr. 10-12, Erlangen 91054, Germany.

Received: 3 December 2013 Accepted: 15 May 2014 Published: 16 June 2014

\section{References}

1. Miyauchi A, Kuma K, Matsuzuka F, Matsubayashi S, Kobayashi A, Tamai H, Katayama S: Intrathyroidal epithelial thymoma: an entity distinct from squamous cell carcinoma of the thyroid. World J Surg 1985, 9:128-135.

2. Chan JK, Rosai J: Tumors of the neck showing thymic or related branchial pouch differentiation: a unifying concept. Hum Pathol 1991, 22:349-367.

3. Cheuk W, Chan JKC, Dorfmann DM, Giordano T: Spindle Cell Tumour With Thymus-Like Differentiation. In World Health Organization Classification of Tumours. Tumours of Endocrine Organs. Edited by DeLellis RA, Lloyd RV, Heitz PU, Eng C. Lyon: IARC Press; 2004:96-97.

4. Ito Y, Miyauchi A, Nakamura Y, Miya A, Kobayashi K, Kakudo K: Intrathyroid Epithelial Thymoma/Carcinoma Showing Thymus-Like Differentiation (CASTLE): Its Clinicopathological Characteristics. In Recent Advances in Thyroid Cancer Research. Kerala: Transworld Research Network; 2006:151-164.

5. Carcangiu ML, Steeper T, Zampi G, Rosai J: Anaplastic thyroid carcinoma: a study of 70 cases. Am J Clin Pathol 1985, 83:135-158.

6. Alexiev BA, Drachenberg CB, Burke AP: Thymomas: a cytological and immunohistochemical study, with emphasis on lymphoid and neuroendocrine markers. Diagn Pathol 2007, 2:13.

7. Veits L, Mechtersheimer G, Steger C, Freitag J, Mikuz G, Schmid KW, Hofmann W, Schirmacher P, Hartmann A, Rieker RJ: Chromosomal imbalances in carcinoma showing thymus-like elements (CASTLE). Virchows Arch 2011, 459:221-226.

8. Henley JD, Cummings OW, Loehrer EJ Sr: Tyrosin kinase receptor expression in thymomas. J Cancer Res Clin Oncol 2004, 130:222-224.

9. Giaccone G: Treatment of malignant thymoma. Curr Opin Oncol 2005, 17:140-146.

10. Ströbel P, Marx A, Zettl A, Muller-Hermelink HK: Thymoma and thymic carcinoma: an update of the WHO classification 2004. Surg 2004 35:805-811. 
11. Rieker RJ, Joos S, Mechtersheimer G, Blaeker H, Schnabel PA, Morresi-Hauf A, Hecker E, Thomas M, Dienemann H, Schirmacher P, Kern MA: COX-2 upregulation in thymomas and thymic carcinomas. Int J Cancer 2006, 119:2063-2070.

12. Rieker RJ, Schnabel PA, Mechtersheimer G, Thomas M, Dienemann H, Schirmacher $P$, Kern MA: COX-2 expression in thymomas and thymic carcinomas: a novel therapeutic target? Diagn Pathol 2007, 2(Suppl 1):S3.

13. Ma Y, Li Q, Cui W, Miao N, Liu X, Zhang W, Zhang C, Wang J: Expression of c-Jun, p73, Casp9, and N-ras in thymic epithelial tumors: relationship with the current WHO classification systems. Diagn Pathol 2012, 7:120.

14. Pan CC, Chen PC, Chiang H: KIT (CD117) is frequently overexpressed in thymic carcinomas but is absent in thymomas. J Pathol 2004, 20:375-381.

15. Ströbel P, Hartmann M, Jakob A, Mikesch K, Brink I, Dirnhofer S, Marx A: Thymic carcinoma with overexpression of mutated KIT and the response to imatinib. N Engl J Med 2004, 350:2625-2626.

16. Buti S, Donini M, Sergio P, Garagnani L, Schirosi L, Passalacqua R, Rossi G: Impressive response with imatinib in a heavily pretreated patient with metastatic c-KIT mutated thymic carcinoma. J Clin Oncol 2011, 29:803-805.

17. Girard N: Thymic tumors: relevant molecular data in the clinic. J Thorac Oncol 2010, 5:291-295

18. Pescarmona E, Pisacane A, Pignatelli E, Baroni CD: Expression of epidermal and nerve growth factor receptors in human thymus and thymomas. Histopathology 1993, 23:39-44.

19. Gilhus NE, Jones M, Turley H, Gatter KC, Nagvekar N, Newsom-Davis J, Willcox N: Oncogene proteins and proliferation antigens in thymomas: increased expression of epidermal growth factor receptor and Ki67 antigen. J Clin Pathol 1995, 48:447-455.

20. Henley JD, Koukoulis GK, Loehrer PJ Sr: Epidermal growth factor receptor expression in invasive thymoma. J Cancer Res Clin Oncol 2002, 128:167-170.

21. Suzuki E, Sasaki H, Kawano O, Endo K, Haneda H, Yukiue H, Kobayashi Y, Yano M, Fujii Y: Expression and mutation statuses of epidermal growth factor receptor in thymic epithelial tumors. Jpn J Clin Oncol 2006, 36:351-356.

22. Meister M, Schirmacher $P$, Dienemann $H$, Mechtersheimer $G$, Schnabel PA, Kern MA, Herpel E, Xu EC, Muley T, Thomas M, Rieker RJ: Mutational status of the epidermal growth factor receptor (EGFR) gene in thymomas and thymic carcinomas. Cancer Lett 2007, 248:186-191.

23. Yoh K, Nishiwaki Y, Ishii G, Goto K, Kubota K, Ohmatsu H, Niho S, Nagai K, Saijo N: Mutational status of EGFR and KIT in thymoma and thymic carcinoma. Lung Cancer 2008, 62:316-320.

24. Aisner SC, Dahlberg S, Hameed MR, Ettinger DS, Schiller JH, Johnson DH, Aisner J, Loehrer PJ: Epidermal growth factor receptor, C-Kit, and Her2/ neu immunostaining in advanced or recurrent thymic epithelial neoplasms staged according to the 2004 World Health Organization in patients treated with octreotide and prednisone: an Eastern Cooperative Oncology Group Study. J Thorac Oncol 2010, 5:885-892.

25. Girard N, Shen R, Guo T, Zakowski MF, Heguy A, Riely GJ, Huang J, Lau C, Lash AE, Ladanyi M, Viale A, Antonescu CR, Travis WD, Rusch W, Kris MG, Pao W: Comprehensive genomic analysis reveals clinically relevant molecular distinctions between thymic carcinomas and thymomas. Clin Cancer Res 2009, 15:6790-6799.

26. Yamaguchi H, Soda H, Kitazaki T, Tsukamoto K, Hayashi T, Kohno S: Thymic carcinoma with epidermal growth factor receptor gene mutations. Lung Cancer 2006, 52:261-262.

27. Janne PA, Engelman JA, Johnson BE: Epidermal growth factor receptor mutations in nonsmall-cell lung cancer: implications for treatment and tumor biology. J Clin Oncol 2005, 23:3227-3234.

28. Kurup A, Burns M, Dropcho S, Pao W, Loehrer PJ: Phase II study of gefitinib treatment in advanced thymic malignancies [abstract]. J Clin Oncol 2005, 23:s7068.

29. Sandler RS, Halabi S, Baron JA, Budinger S, Paskett E, Keresztes R, Petrelli N, Pipas JM, Karp DD, Loprinzi CL, Steinbach G, Schilsky R: A randomized trial of aspirin to prevent colorectal adenomas in patients with previous colorectal cancer. N Engl J Med 2003, 348:883-890

30. Malka D, Pacault V, De Baere T, Ducreux M, Boige V: Antitumoral effect of celecoxib in hepatocellular carcinoma. J Clin Oncol 2005, 23:4805-4806.

31. Kulkarni S, Rader JS, Zhang F, Liapis H, Koki AT, Masferrer JL, Subbaramaiah K, Dannenberg AJ: Cyclooxygenase-2 is overexpressed in human cervical cancer. Clin Cancer Res 2001, 7:429-434.

32. Pai R, Soreghan B, Szabo IL, Pavelka MP, Baater D, Tarnawski AS: Prostaglandin E2 transactivates EGF receptor: a novel mechanism for promoting colon cancer growth and gastrointestinal hypertrophy. Nat Med 2002, 8:289-293.

33. Pai R, NakamuraT MWS, Tarnawski AS: Prostaglandins promote colon cancer invasion; signalling by cross-talk between two distinct growth factor receptors. FASEB J 2003, 17:1640-1647.

34. Huh YH, Kim SH, Kim SJ, Chun JS: Differentiation status-dependent regulation of cyclooxygenase-2 expression and prostaglandin E2 production by epidermal growth factor via mitogen-activated protein kinase in articular. J Biol Chem 2003, 278:9691-9697.

35. Ströbel P, Bargou R, Wolff A, Spitzer D, Manegold C, Dimitrakopoulou-Strauss A, Strauss L, Sauer C, Mayer F, Hohenberger P, Marx A: Sunitinib in metastatic thymic carcinomas: laboratory findings and initial clinical experience. Br J Cancer 2010, 103:196-200.

doi:10.1186/1746-1596-9-116

Cite this article as: Veits et al:: KRAS, EGFR, PDGFR-a, KIT and COX-2 status in carcinoma showing thymus-like elements (CASTLE). Diagnostic Pathology 2014 9:116.

\section{Submit your next manuscript to BioMed Central and take full advantage of:}

- Convenient online submission

- Thorough peer review

- No space constraints or color figure charges

- Immediate publication on acceptance

- Inclusion in PubMed, CAS, Scopus and Google Scholar

- Research which is freely available for redistribution 